\title{
Pendidikan Kesehatan Tuberkulosis untuk Kader Kesehatan
}

\author{
Desy Indra Yani, Neti Juniarti, Mamat Lukman \\ Fakultas Keperawatan Universitas Padjadjaran \\ Email: desy.indra.yani@unpad.ac.id
}

\begin{abstract}
Abstrak
Tuberkulosis (TB) merupakan penyakit menular dengan angka kesakitan dan kematian yang tinggi di Indonesia. Banyak kasus TB tidak terdiagnosa dan tidak dilaporkan. Penyakit TB juga sering telat terdiagnosa dan diobati walau orang-orang dengan suspek TB teridentifikasi. Oleh karena itu, perlu melibatkan kader kesehatan sebagai bagian dari masyarakat dalam pengendalian TB melalui pemberian pendidikan kesehatan untuk meningkatkan pengetahuan tentang TB. Tujuan pengabdian masyarakat ini adalah untuk mengimplementasikan pendidikan kesehatan berbasis masyarakat untuk meningkatan pengetahuan TB sebagai upaya pencegahan dan pengendalian TB di Kabupaten Karawang. Peserta kegiatan ini berjumlah 48 orang. Hasil kegiatan ini berhasil meningkatkan pengetahuan TB dan pengetahuan penularan TB. Pengetahuan kader kesehatan yang baik diharapkan dapat membantu memberikan edukasi kesehatan masyarakat tentang TB. Pemberdayaan kader kesehatan dalam membantu pengendalian dan pencegahan TB dapat terus dilanjutkan dengan evaluasi berkala.
\end{abstract}

Kata kunci: Kader kesehatan, pendidikan kesehatan, pengetahuan, tuberkulosis.

\begin{abstract}
Tuberculosis $(T B)$ is an infectious disease with high morbidity and mortality rates in Indonesia. Many TB cases are not diagnosed and not reported. TB is also often diagnosed and treated late even though people with suspected TB are identified. Therefore, it is necessary to involve health cadres as part of the community in TB control through the provision of health education to increase knowledge about TB. The purpose of this community service was to implement community-based health education to increase TB knowledge as an effort to prevent and control TB in Karawang Regency. The participants of this activity were 48 people. The results of this activity succeeded in increasing TB knowledge and knowledge of TB transmission. Knowledge of good health cadres is expected to help provide public health education about TB. Empowerment of health cadres in helping control and prevent TB could be prolonged with periodic evaluation.
\end{abstract}

Keywords: health cadres, health education, knowledge, tuberculosis 


\section{Pendahuluan}

Angka kejadian TB mengalami penurunan dari tahun ke tahun. Hal ini terbukti dari tercapainya target MDGs untuk angka insidensi TB di dunia. Walau demikian, angka prevalensi dan kematian TB belum mencapai target. Indonesia merupakan negara ketiga dengan kasus TB terbanyak di dunia. Peringkat ini menurun dari tahun 2017 yang berada di peringkat kedua. Angka insidensi TB pada tahun 2017 adalah 319 per 100.000 penduduk (World Health Organization (WHO), 2018). TB sebagai penyakit infeksi masih menjadi beban kesehatan masyarakat di Indonesia. TB merupakan penyakit terbanyak kedua di Kabupaten karawang. Jumlah kasus TB sebanyak 1.291 kasus pada tahun 2015.

TB mendapatkan berbagai tantangan dan terdapat lima prioritas dalam pengendalian TB. Lima prioritas tantangan tersebut adalah: 1) Kasus TB diperkirakan hilang setiap tahunnya karena tidak didiagnosis dan diberitahukan kepada sistem kesehatan; 2) MDR-TB harus ditangani sebagai krisis mengingat potensinya untuk menghalangi pencapaian tujuan saat ini; 3) Eepidemi TB / HIV membutuhkan respon yang dipercepat berdasarkan integrasi layanan yang lebih dalam dan lebih komprehensif antara program yang dikelola secara terpisah; 4) dukungan finansial untuk memerangi TB sangat penting untuk menutup kesenjangan sumber daya; 5) penelitian perlu diintensifkan di seluruh spektrum dari dasar menuju pembangunan pipa dan penelitian operasional, agar berhasil menghasilkan diagnosa baru, obat-obatan dan akhirnya vaksin dan serapan yang cepat dari inovasi tersebut (Raviglione \& Sulis, 2016). Kegiatan PPM ini dilakukan sebagai upaya mengatasi banyaknya kasus TB yang hilang karena gagal didiagnosis. Pengetahuan TB memiliki peranan penting dalam mengatasi tantangan ini.

Pengetahuan dan persepsi TB masih rendah di masyarakat. Pengetahuan TB yang buruk merupakan permasalahan umum yang sering terjadi pada negara berkembang dengan beban TB yang tinggi (Zein, Suhariadi, \& Hendriani, 2017). Pengetahuan TB juga rendah pada pasien TB yang mengalami kegagalan pengobatan terutam pada topik bagaimana penularan TB, pengobatan TB dan lama pengobatan (Putera, Pakasi, \& Karyadi, 2015). Peelitian lain menunjukkan bahwa masyarakat memiliki pengetahuan yang kurang baik mengenai penyebab dan penularan TB (Dewi, Barclay, Passey, \& Wilson, 2016). Pengetahuan tentang TB yang terbatas ini dan kesalahapahaman mengenai TB memiliki dampak negatif dalam mempersepsikan TB dan menyebabkan timbulnya stigma negatif terhadap TB. 
Stigma adalah salah satu dari banyak faktor yang menghambat pengendalian tuberkulosis dengan secara negatif mempengaruhi keterlambatan diagnosait dan kepatuhan pengobatan. Pemerintah telah berupaya mengurangi kejadi kasus TB yang tinggi di Indonesia dengan melakukan pengendalian epidemi dan mengurangi stigma. Stigma negatig terhadap TB perlu diatasi karena konsekuensi sosialnya menghambat kontrol TB yang efektif yang menyebabkan diagnosis tertunda dan kepatuhan pengobatan yang buruk. Akibatnya, ini mengarah pada hasil pengobatan yang buruk dan kegagalan pengobatan, bahan bakar transmisi yang sedang berlangsung, dan memfasilitasi munculnya resistansi obat TB (Cremers et al., 2015). Interevensi kesehatan diperlukan bagi masyarakat dalam mengatasi stigma negatif dan pengetahuan yang terbatas.

Pendidikan kesehatan adalah intervensi yang tapat dalam meningkatkan pengetahuan masyarakat tentang TB dan merupakan sebagai salah atu intervensi dalam pengendalian TB. Pendidikan kesehatan TB dibutuhkan sebagai upaya untuk memperkuat penyebaran informasi yang akurat untuk mempromosikan pengetahuan dan sikap TB yang sehat (Kigozi, Heunis, Engelbrecht, Janse van Rensburg, \& van Rensburg, 2017). Pendidikan kesehatan yang dilakukan pada siswa berhasil meningkatkan pengetahuan mereka terutama berkaitan dengan pengobatan TB (Gopichandran, Roy, Sitaram, Karthick, \& John, 2010). Pendidikan kesehatan yang diberikan pada anggota keluarga berhasil ditingkatan dengan menggunakan media video (Wilson, Ramos, Castillo, F. Castellanos, \& Escalante, 2016). Hal ini menunjukkan bahwa pendidikan kesehatan berhasil meningkatkan pengetahuan masyarakat.

Berdasarkan penejelasan di atas, penulis melakukan pengabdian masyarakat ini. Tujuan artikel ini adalah untuk menganalisi pengaruh program pendidikan kesehatan TB berbasis masyarakat untuk peningkatan pengetahuan TB di Kabupaten Karawang.

\section{Metode}

Metode yang digunakan dalan kegiatan ini adalah pendidikan kesehatan interaktif. Pelaksana PPM membuat list pertanyaan TB di kertas yang ditempelkan di dinding, kemudian peserta diajak berpartisipasi melalui aktivitas kelompok untuk menjawab pertanyaan tersebut pada pilihan jawaban yang tersedia dalam bentuk kertas-kertas kecil dan jawaban tersebut ditempel pada setiap pertanyaan yang diberikan. Pelaksana PPM akan mengevaluasi jawaban dari peserta dari tempelan jawaban yang ditempel oleh peserta. Sasaran kegiatan ini adalah kader kesehatan dan ibu PKK di Kecamatan Tempuran Jawa 
Barat. Pendidikan kesehatan dilakukan secara kelompok. Setiap kelompok difasilitasi oleh tim pelakasana pengabdian. Pelaksanaan kegiatan dibagi menjadi tiga tahap yaitu: 1) pre test tentang pengetahuan TB, stigma TB, dan skrining gejala TB; 2) Pemberian materi tentang kader kesehatan dan kader kesehatan TB dan dilanjutkan dengan

Evaluasi kegiatan dilakukan dengan menggunakan indikator tingkat pengetahuan TB. Pengetahuan TB diukur dengan kuosioner pada saat sebelum dan setelah pemberian pendidikan kesehatan. Kuesioner pengetahuan terdiri dari 14 pernyataan dengan pilihan jawaban benar dan salah. Tingkat pengetahuan dikategorikan menjadi dua yaitu: 1) pengetahuan baik jika responden memiliki skor di atas percentil 75; dan 2) kategori pengetahuan kurang baik jika responden memiliki skor kurang dari percentile 75. Analisa data dilakukan dengan menggunakan pendekatan kuantitatif dengan membandingkan skor pengetahuan sebelum dan setelah pendidikan kesehatan.

Pelaksanaan pengabdian masyarakat ini melalui beberapa tahapan, yaitu:

1. Fase persiapan

Pada fase ini, pengusul PKM mengumpulkan data dari puskesmas dan kemudian mapping kader kesehatan di wilayah ini. Pertemuan kelompok yang meliputi pengusul PKM, petugas kesehatan, petugas PKK yang terdiri dari kader kesehatan dari setiap desa, dan pimpinan komunitas yang diwakili oleh petugas dari Kecamatan Tempuran Kabupaten Karawang. Kegiatan utama dari pertemuan ini adalah melakukan pengkajian jumlah kader kesehatan untuk melakukan pengendalian dan pengobatan TB di wilayah ini dan kemudian diikuti oleh analisa data yang difasilitasi oleh pengusul PPM ini.

2. Fase pelaksanaan

Sasaran pengabdian ini adalah masyarakat dan kader kesehatan. Sebelum melakukan kegiatan utama pada masyarakat dan pasien, kader kesehatan dilatih oleh pelaksana pengabdian ini. Kader kesehatan yang telah dilatih mengimplementasikan program skrining berbasis masyarakat yang meliputi pelatihan kader kesehatan skrining TB, pendidikan kesehatan, skrining TB, dan tindak lanjut skrining TB. Semua kegiatan ini difasilatasi oleh pengusul pengabdian dan diawasi oleh petugas kesehatan. Kader kesehatan memiliki peranan kunci dalam pelaksanaan program skrining berbasis komunitas. Adapun peran kader kesehatan, yaitu:

1. Pendukung skrining

2. Mendukung dan memotivasi masyarakat

3. Dukungan umum 

4. Pendeteksian kasus
5. Evaluasi
6. Pelaksana tindak lanjut

3. Fase evaluasi

Evaluasi dilakukan dengan dua metode, yaitu evaluasi proses dan evaluasi hasil. Evaluasi proses terdiri dari pelaksanaan setiap aktivitas, kehadiran peserta, anstusias peserata, keaktifan, dan media dan strategi yang digunakan pada setiap aktivitas. Evaluasi hasil terdiri dari pengetahuan, persepsi terhadap TB dan kepatuhan pelaksanaan program. Evaluasi ini dilakukan pada semua target.

\section{Hasil}

Kegiatan pendidikan kesehatan dilaksanakan di kantor Kecamatan Tempuran Kabupaten Karawang Provinsi Jawa Barat. Hasil pengabdian pada masyarakat ini akan dibahas berdasarkan literature yang ada. Terdapat 48 kader kesehatan ibu PKK terlibat dalam kegiatan ini. Rata-rata usia peserta adalah 38,25 tahun $(S D=8,03)$. Semua peserta adalah perempuan dan beragama Islam. Mayoritas peserta adalah menikah, bersuku Sunda, menikah, tidak memiliki masalah kesehatan, tidak pernah menderita TB dan tidak pernah mengikuti pendidikan kesehatan TB (Tabel 1.).

Tabel 1. Frekuensi dan Persentase Data Demografi Kader Kesehatan di Kabupaten Karawang $(\mathrm{N}=48)$

\begin{tabular}{lcc}
\hline \multicolumn{1}{c}{ Variabel } & Frekuensi & Persentase \\
\hline Usia & $\mathrm{M}=38,25$ & $\mathrm{SD}=8,03$ \\
Jenis Kelamin & 1 & 2,1 \\
$\quad$ Laki-laki & 47 & 97,9 \\
$\quad$ Perempuan & & \\
Status Kawin & 46 & 95,8 \\
$\quad$ Menikah & 2 & 4,2 \\
$\quad$ Janda/ duda & & 100,0 \\
Agama & 48 & \\
Islam & & \\
Suku & & \\
\hline
\end{tabular}


Desy Indra Yani: Pendidikan Kesehatan Tuberkulosis untuk Kader Kesehatan

\begin{tabular}{|c|c|c|}
\hline Variabel & Frekuensi & Persentase \\
\hline Sunda & 42 & 87,5 \\
\hline Jawa & 5 & 10,4 \\
\hline Batak & 1 & 2,1 \\
\hline \multicolumn{3}{|l|}{ Pekerjaan } \\
\hline Tidak ada & 20 & 41,7 \\
\hline Ada & 28 & 58,3 \\
\hline \multicolumn{3}{|l|}{ Pendidikan } \\
\hline Tidak sekolah & 1 & 2,1 \\
\hline $\mathrm{SD}$ & 12 & 25,0 \\
\hline SLTP & 16 & 33,3 \\
\hline SLTA & 15 & 31,3 \\
\hline Universitas & 4 & 8,3 \\
\hline \multicolumn{3}{|l|}{ Kepemilikan asuransi } \\
\hline \multicolumn{3}{|l|}{ kesehatan } \\
\hline $\mathrm{Ya}$ & 21 & 43,8 \\
\hline Tidak & 27 & 56,3 \\
\hline \multicolumn{3}{|l|}{ Memiliki Masalah } \\
\hline \multicolumn{3}{|l|}{ Kesehatan } \\
\hline $\mathrm{Ya}$ & 4 & 83 \\
\hline Tidak & 44 & 91,7 \\
\hline \multicolumn{3}{|l|}{ Pernah menderita TB } \\
\hline $\mathrm{Ya}$ & 1 & 2,1 \\
\hline Tidak & 47 & 97,9 \\
\hline \multicolumn{3}{|c|}{ Pernah mengikuti pelatihan } \\
\hline $\mathrm{Ya}$ & 7 & 14,6 \\
\hline Tidak & 41 & 85,4 \\
\hline
\end{tabular}

Kegiatan ini juga melaksanakan skrining gejala TB. Pernyataan skrining TB yang paling banyak yang dialami peserta adalah batuk berdahak $(43,8 \%)$ dan demam, kedinginan atau keringat malam untuk alasan yang tidak jelas $(43,8 \%)$. Pernyataan skrining TB yang paling sedikit dialami responden adalah pernah mendapatkan TB $(8,3 \%)$ dan memiliki 
masalah medis atau sedang minum obat yang menekan sistem imun (daya tahan tubuh) anda $(10,8 \%)($ table 2$)$.

Tabel 2. Frekuensi dan Persentase Skrining Gejala TB pada Kader Kesehatan di Kabupaten Karawang $(\mathrm{N}=48)$

\begin{tabular}{lcc}
\hline \multicolumn{1}{c}{ Variabel } & Frekuensi & Persentase \\
\hline Batuk produktif lebih dari 3 minggu & 16 & 33,3 \\
Batuk berdahak & 21 & 43,8 \\
Penurunan berat badan yang tidak direncanakan & 18 & 37,5 \\
Demam, kedinginan atau keringat malam untuk alasan yang & 21 & 43,8 \\
tidak jelas & & \\
Nafas pendek yang terus-menerus & 15 & 31,3 \\
Kelelahan yang tidak dapat dijelaskan & 19 & 39,6 \\
Nyeri dada & 18 & 37,5 \\
Pernah kontak dengan penderita tuberculosis aktif dalam & 8 & 16,7 \\
setahun terakhir & & \\
Memiliki masalah medis atau sedang minum obat yang & 5 & 10,4 \\
menekan sistem imun (daya tahan tubuh) anda & & 8,3 \\
Pernah mendapatkan pengobatan TB & 4 & \\
\hline
\end{tabular}

Kegiatan ini mengukur pengetahuan $\mathrm{TB}$, pengetahuan penularan $\mathrm{TB}$, stigma $\mathrm{TB}$ indikator sebagai data standar. Rata-rata pengetahuan TB adalah 12,29 dengan skor tertinggi adalah 14. Rata-rata pengetahuan TB adalah 6,60 dengan skor tertinggi adalah 9. Rata-rata stigma TB yang dipersepsikan oleh masyarakat adalah 27,77 dengan skor tertinggi adalah 44 dan rata-rata stigma TB yang dipersepsikan oleh masyarakat adalah 30,56 dengan skor tertinggi adalah 48 (Tabel 3).

Banyak pasien melaporkan stigma yang dialami dan / atau diantisipasi. Stigma yang diantisipasi harus dianggap serius seperti stigma yang dialami karena mencerminkan prevalensi pemahaman dan praktik stigmatisasi di masyarakat. Oleh karena itu, masyarakat perlu diberikan pendidikan kesehatan agar memiliki pengetahuan yang baik dan stigma masyarakat terhadap pasien berkurang. Hasil penelitian menunjukkan bahwa pasien menyebutkan berulang kali bahwa anggota komunitas memiliki pengetahuan (biomedis) yang tidak memadai dan memiliki kesalahpahaman TB (Cremers et al., 2015). Oleh karena 
itu, pendidikan kesehatan TB yang telah diberikan kepada kader kesehatan dapat diteruskan kepada masyarakat dengan merangsang diskusi dan meningkatkan kesadaran mengenai stigma.

Tabel 3. Mean dan SD Pengetahuan TB, Pengetahuan Penularan TB, dan Stigma TB, Kader Kesehatan di Kabupaten Karawang $(\mathrm{N}=48)$

\begin{tabular}{lccccc}
\hline \multicolumn{1}{c}{ Variabel } & Rentang Skor & Minimum & Maksimum & Mean & SD \\
\hline $\begin{array}{l}\text { Pengetahuan TB } \\
\text { Pre-test }\end{array}$ & $0-14$ & 0 & 14 & 12,29 & 2,30 \\
$\begin{array}{l}\text { Post-test } \\
\text { Pengetahuan }\end{array}$ & $0-14$ & 11 & 14 & 13,60 & 0,71 \\
penularan TB & & & & & \\
Pre-test & $0-9$ & 3 & 9 & 6,60 & 1,32 \\
Post-test & $0-9$ & 5 & 9 & 7,35 & 1,02 \\
Stigma TB & & 30 & 77 & 57,83 & 1,09 \\
Stigma TB dari & $11-44$ & 17 & 41 & 27,27 & 4,04 \\
masyarakat & & & & & \\
Stigma TB dari & $12-48$ & 13 & 40 & 30,56 & \\
pasien & & & & & \\
\hline
\end{tabular}

Pendidikan kesehatan berhasil merubah pengetahuan TB $($ Mean $=12,29, \mathrm{SD}=2,30)$ dan pengetahuan penularan TB $($ Mean $=6,60, \mathrm{SD}=1,32)$ peserta kegiatan pendidikan kesehatan jika dibandingkan dengan skor pengetahuan TB Mean $=13,60, \mathrm{SD}=0,71$ ) dan pengetahuan penularan TB $($ Mean $=7,35, \mathrm{SD}=1,02)($ Tabel 4).

Tabel 4. Pengaruh program pendidikan kesehatan TB terhadap pengetahuan TB dan pengetahuan penularan TB pada Kader Kesehatan di Kabupaten Karawang $(N=48)$

\begin{tabular}{lcccccc}
\hline \multirow{2}{*}{ Variabel } & \multicolumn{2}{c}{ Pretest } & \multicolumn{2}{c}{ Posttest } & t-test & p-value \\
\cline { 2 - 5 } & $\mathrm{M}$ & $\mathrm{SD}$ & $\mathrm{M}$ & $\mathrm{SD}$ & & \\
\hline Pengetahuan & 12,29 & 2,30 & 13,60 & 0,71 & $-3,86$ & 0,00 \\
TB & & & & & & \\
$\begin{array}{l}\text { Pengetahuan } \\
\text { penularan }\end{array}$ & 6,60 & 1,32 & 7,35 & 1,02 & $-4,51$ & 0.00 \\
\hline
\end{tabular}


TB

\section{Pembahasan}

Pendidikan kesehatan merupakan dirancang untuk membantu individu dan komunitas untuk meningkatkan kesehatan melalui peningkatan pengetahuan yang nantinya memengaruhi sikap dan perilaku individu dan komunitas tersebut. Pendidikan kesehatan adalah proses belajar-mengajar yang berkesinambungan, dinamis, kompleks dan terencana sepanjang umur dan dalam pengaturan yang berbeda yang dilaksanakan melalui klien yang adil dan dinegosiasikan 'kemitraan' profesional kesehatan untuk memfasilitasi dan memberdayakan orang tersebut untuk mempromosikan / memulai gaya hidup terkait perubahan perilaku yang mempromosikan hasil status kesehatan yang positif (Pueyo-Garrigues et al., 2019). Pendidikan kesehatan yang diberikan pada PPM ini telah dirancang untuk mencapai kemitraan professional antara edukator dan kader kesehatan.

Pendidikan kesehatan yang dilaksanakan pada PPM ini berupa aktivitas kelompok dengan melibatkan partisipasi aktif kader, menggunakan alat bantu edukasi berupa audiovisual dan Tanya-jawab. Berbagai pelaksanaan PPM telah terbukti berhasil meningkatkan pengetahun peserta melalui pendidikan kesehatan TB. Kader kesehatan mengalami peningkatan pengetahuan tentang TB secara signifikan dari skor pretest dengan nilai mean $=12,29(\mathrm{SD}=2,30)$ menjadi lebih baik pada skor posttest dengan mean $=13,60(\mathrm{SD}=0,71)$. Guru-guru yang telah diberikan pendidikan kesehatan TB memiliki peningkatan rata-rata pengetahuan sebesar 50,92 ( $\mathrm{SD}=0,45)$ (Nurhidayah, Mediani, \& MArdiyah, 2018). Peningkatan pengetahuan kader pada PPM saat ini tidak terlalu tinggi dibandingkan dengan pendidikan kesehatan pada guru. Perbedaan skor peningkatan pengetahuan ini dipengaruhi oleh level pendidikan peserta PPM. Guru memiliki level pendidikan sarjana sedangkan hanya $8,3 \%$ kader kesehatan yang memiliki level pendidikan tinggi di universitas. Hasil berbeda ditemukan pada pendidikan kesehatan diabetes yang diberikan pada kader kesehatan yang tidak signifikan meningkatkan pengetahuan kader kesehatan (Sari, Yamin, \& Sari, 2018).

Keberhasilan pendidikan kesehatan dipengaruhi oleh kemampuan koginitif peserta. Faktor socio-demografi merupakan salah satu fakto yang memengaruhi kemampuan kognitif yang meliputi usia, jenis kelamin dan level pendidikan(de Azeredo Passos et al., 2015). Dari tiga faktor ini ditemukan pada penelitian lain bahwa faktor level pendidikan merupakan faktor yang paling ebrdampak terhadap kemampuan kognitif (Fichman et al., 
2009). Kemampuan kognitif peserta akan membantu peserta memahami materi yang disampaikan dalam pendidikan kesehatan.

Kader kesehatan TB telah mengalami peningkatan pengetahuan TB. Hal ini akan membantu dalam pencegahan dan pengendalian TB. Kader TB dengan pengetahuan yang baik melalui pelatihan akan dapat melaksanakan perannya dengan baik dalam implementasi program-program TB (Yani, Hidayat, \& Sari, 2018)Hal ini akan membantu dalam pencegahan dan pengendalian TB. Kader TB dengan pengetahuan yang baik melalui pelatihan akan dapat melaksanakan perannya dengan baik dalam implementasi programprogram TB (Yani et al., 2018).

\section{Simpulan}

Pendidikan kesehatan ini berhasil meningkatkan pengetahuan TB dan penularan TB pada kader kesehatan di Kecamatan Tempuran Kabupaten Karawang. Pendidikan kesehatan yang interaktif berhasil memberikan pengalaman belajar baru bagi kader kesehatan dan dapat diaplikasi ketika kader memberikan pendidikan kesehatan TB pada masyarakat.

\section{Ucapan Terima kasih}

Penulis mengucapakan terima kasih kepada Universitas Padjadjaran terutama Direktorat Penelitian dan Pengabdian Kepada Mssyarakat UNPAD atas dana PPM hibah internal Unpad tahun 2018.

\section{Daftar Pustaka}

Cremers, A. L., de Laat, M. M., Kapata, N., Gerrets, R., Klipstein-Grobusch, K., \& Grobusch, M. P. (2015). Assessing the consequences of stigma for tuberculosis patients in urban Zambia. PloS One, 10(3), e0119861-e0119861. https://doi.org/10.1371/journal.pone.0119861.

de Azeredo Passos, V. M., Giatti, L., Bensenor, I., Tiemeier, H., Ikram, M. A., de Figueiredo, R. C., ... Barreto, S. M. (2015). Education plays a greater role than age in cognitive test performance among participants of the Brazilian Longitudinal Study of $\begin{array}{llllll}\text { Adult Health (ELSA-Brasil). BMC Neurology, } & 191 .\end{array}$ https://doi.org/10.1186/s12883-015-0454-6.

Dewi, C., Barclay, L., Passey, M., \& Wilson, S. (2016). Improving knowledge and behaviours related to the cause, transmission and prevention of Tuberculosis and early case detection: a descriptive study of community led Tuberculosis program in Flores, Indonesia. BMC Public Health, 16(1), 740. https://doi.org/10.1186/s12889-016-34484. 
Fichman, H. C., Fernandes, C. S., Nitrini, R., Lourenco, R. A., Paradela, E. M. de P., Carthery-Goulart, M. T., \& Caramelli, P. (2009). Age and educational level effects on the performance of normal elderly on category verbal fluency tasks. Dementia \& Neuropsychologia, 3(1), 49-54. $\quad$ https://doi.org/10.1590/S198057642009DN30100010.

Gopichandran, V., Roy, P., Sitaram, A., Karthick, \& John, K. (2010). Impact of a Simple Educational Intervention on the Knowledge and Awareness of Tuberculosis among High School children in Vellore, India. Indian Journal of Community Medicine: Official Publication of Indian Association of Preventive \& Social Medicine, 35(1), 174-175. https://doi.org/10.4103/0970-0218.62589.

Kigozi, N. G., Heunis, J. C., Engelbrecht, M. C., Janse van Rensburg, A. P., \& van Rensburg, H. C. J. D. (2017). Tuberculosis knowledge, attitudes and practices of patients at primary health care facilities in a South African metropolitan: research towards improved health education. BMC Public Health, 17(1), 795. https://doi.org/10.1186/s12889-017-4825-3.

Nurhidayah, I., Mediani, H. S., \& MArdiyah, A. (2018). No TitlePemberdayaan Guru Sekolah dalam Deteksi Dini Tuberkulosis pada Anak Sekolah. Media Karya Kesehatan, 1(2), 185-195.

Pueyo-Garrigues, M., Whitehead, D., Pardavila-Belio, M. I., Canga-Armayor, A., PueyoGarrigues, S., \& Canga-Armayor, N. (2019). Health education: A Rogerian concept analysis. International Journal of Nursing Studies, 94, 131-138. https://doi.org/10.1016/j.ijnurstu.2019.03.005.

Putera, I., Pakasi, T. A., \& Karyadi, E. (2015). Knowledge and perception of tuberculosis and the risk to become treatment default among newly diagnosed pulmonary tuberculosis patients treated in primary health care, East Nusa Tenggara: a retrospective study. BMC Research Notes, 8, 238. https://doi.org/10.1186/s13104-0151209-6.

Raviglione, M., \& Sulis, G. (2016). Tuberculosis 2015: Burden, Challenges and Strategy for Control and Elimination. Infectious Disease Reports, 8(2), 6570. https://doi.org/10.4081/idr.2016.6570.

Sari, C. W. M., Yamin, A., \& Sari, S. P. (2018). No Titlependidikan kesehatan adalah proses belajar-mengajar yang berkesinambungan, dinamis, kompleks dan terencana sepanjang umur dan dalam pengaturan yang berbeda yang dilaksanakan melalui klien yang adil dan dinegosiasikan "kemitraan" profesional keseha. Media Karya Kesehatan, $1(1), 29-38$.

Wilson, J. W., Ramos, J. G., Castillo, F., F. Castellanos, E., \& Escalante, P. (2016). Tuberculosis patient and family education through videography in El Salvador. Journal of Clinical Tuberculosis and Other Mycobacterial Diseases, 4, 14-20. https://doi.org/https://doi.org/10.1016/j.jctube.2016.05.001.

World Health Organization (WHO). (2018). Global Tuberculosis Report 2018. Geneva, Switzerland: World Health Organization. 
Yani, D. I., Hidayat, R. A., \& Sari, C. W. M. (2018). Gambaran Pelaksanaan Peran Kader Tuberkulosis pada Program DOTS di Kecamatan Bandung Kulon. Jurnal Keperawatan Komprehensif, 4(2), 58-67.

Zein, R. A., Suhariadi, F., \& Hendriani, W. (2017). Estimating the effect of lay knowledge and prior contact with pulmonary TB patients, on health-belief model in a high-risk pulmonary TB transmission population. Psychology Research and Behavior Management, 10, 187-194. https://doi.org/10.2147/PRBM.S134034 